\title{
In-Flight Thermal Performance of the Geoscience Laser Altimeter System (GLAS) Instrument
}

\author{
E. Grob, C. Baker and T. McCarthy \\ NASA Goddard Space Flight Center
}

\begin{abstract}
The Geoscience Laser Altimeter System (GLAS) instrument is NASA Goddard Space Flight Center's first application of Loop Heat Pipe technology that provides selectable/stable temperature levels for the lasers and other electronics over a widely varying mission environment.
\end{abstract}

GLAS was successfully launched as the sole science instrument aboard the Ice, Clouds, and Land Elevation Satellite (ICESat) from Vandenberg AFB at 4:45pm PST on January 12, 2003. After SC commissioning, the LHPs started easily and have provided selectable and stable temperatures for the lasers and other electronics.

This paper discusses the thermal development background and testing, along with details of early flight thermal performance data.

\section{INTRODUCTION}

GLAS is a 2-channel laser altimetry and lidar science mission that measures polar ice-sheet topography, cloud and atmospheric properties, and along-track topography over land and water. The infrared pulse $(1064 \mathrm{~nm})$ is used for surface altimetry (precision better than $1 \mathrm{~cm}$ after calibration) and cloud-top measurements, and the green pulse $(532 \mathrm{~nm})$ is used for measurements of thin clouds and aerosols. Using the Global Positioning System (GPS) and onboard star camera (looking out the zenith side of GLAS) and gyroscopes to accurately locate the instrument position and laser pointing direction (within $\sim 1.5$ arc seconds), the altimeter measurement location on the surface of Earth can be accurately determined. The return photons are collected in a $1 \mathrm{~m}$ diameter telescope.

Q-switched Nd:YAG lasers, pulsed at a $40 \mathrm{~Hz}$ repetition rate and a beam divergence of approximately $0.11 \mathrm{mrad}$, provide $70 \mathrm{~m}$ spots on the earth surface spaced $175 \mathrm{~m}$ apart. A series of such laser footprint locations provides a profile of the surface. This height measurement, coupled with precise knowledge of the radial orbit position, will provide the determination of surface topography. Analysis of the sequence of laser spots over time enables the determination of the temporal change in topography that will provide information about ice-sheet mass balance and will support predictions of cryospheric and sea-level responses to future climatic changes.

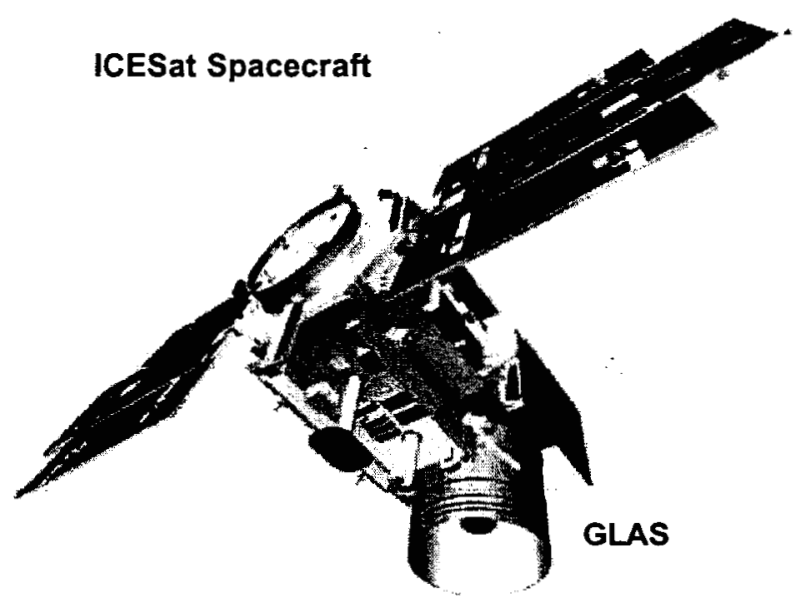

\section{THERMAL DESIGN CHALLENGE}

Primary science requirements for GLAS necessitated the sun-asynchronous $600 \mathrm{~km}$ polar orbit $\left(94^{\circ}\right.$ inclination), where the orbit precesses through a large range of beta angles ${ }^{1}\left(-90^{\circ}<\beta<+90^{\circ} \mathrm{C}\right)$ and includes eclipses for most of the mission. Utilizing a spacecraft bus that was designed as a nadir pointing platform, but flying perpendicular to that orientation for this mission, further complicates the thermal scenarios by necessitating spacecraft yaw maneuvers to maintain adequate solar array illumination and battery temperatures. Figure 1

\footnotetext{
${ }^{1}$ Beta angle is the angle between the orbit plane and the sun
} 
illustrates the many combinations of beta and spacecraft yaw angles. Additionally, the cyclical variation in solar intensity, and increasing absorbed solar heating (due to radiator degradation effects) over mission life, results in a wide range of thermal environmental effects in which stable component temperatures must be maintained throughout the mission.

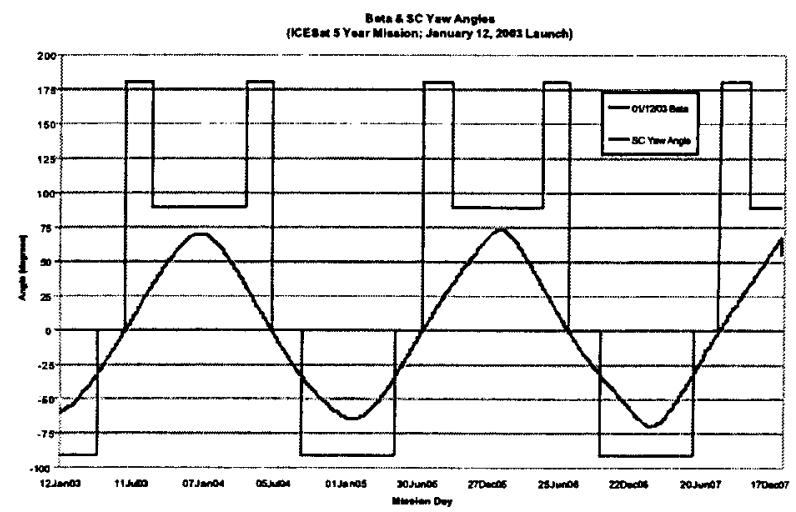

Figure 1 - Thermal Environmental Variations

The science measurement precision requires minimal thermal distortion of the optical benches to maintain the precise alignment of the numerous optical surfaces in the outgoing beam transmit path (Figure 2). Similarly, thermal distortion of the receiver telescope and optics Figure 3) must be minimized to prevent distortion or defocusing of the return image. This stringent control must be accomplished in the widely varying orbital thermal environment where the sun impinges on GLAS from many angles, and the external heating loads range from direct/indirect sun and earth emitted IR to only the latter during eclipses, which are not constant.

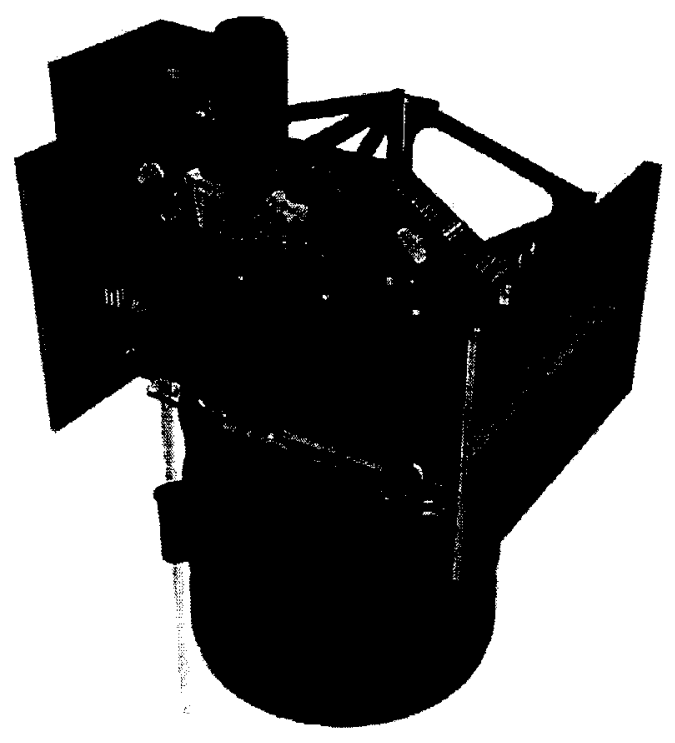

Figure 2 - Laser Transmit Path (LT1 firing)

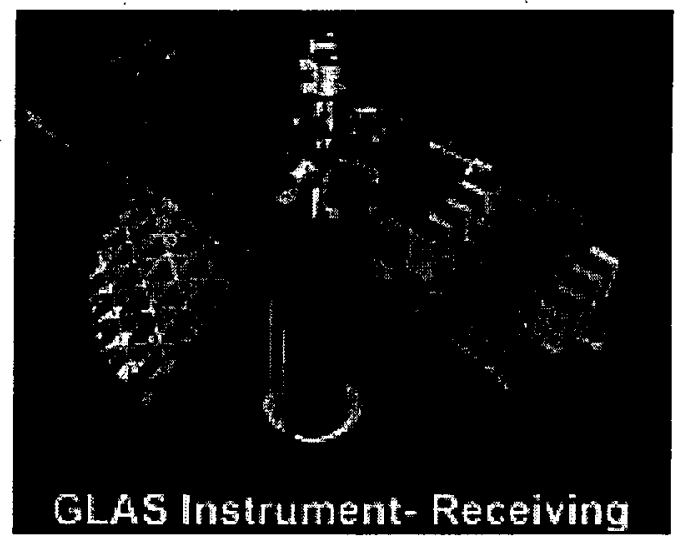

Figure 3 - GLAS Receive Optics Path

Resources available from the SC bus were limited since it was an existing heritage design procured under NASA's Rapid Spacecraft Development Office (RSDO) program. Orbit average power allocated for thermal control was limited to 35 watts (operational) and $150 \mathrm{~W}$ (survival). Because of mass constraints, a selective redundancy philosophy was used, resulting in no TCS hardware redundancy, except for the operational control thermistors and survival heater thermostats.

Packaging of the optical and electronic components was achieved by using two orthogonal composite optical benches (Figure 4) mounted to the spacecraft with three titanium blade flexures to isolate GLAS from spacecraft induced distortion and jitter.

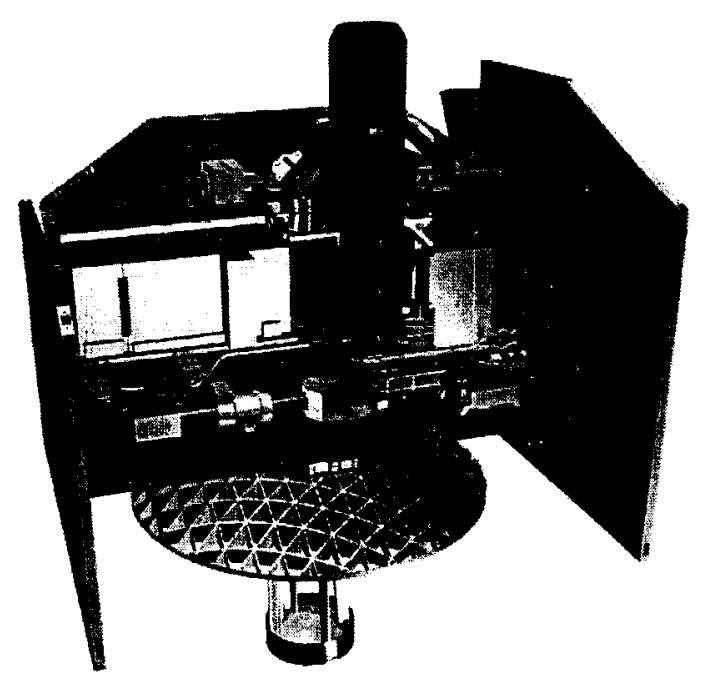

Figure 4 - GLAS Packaging (some structure and MLI removed for clarity) 
In summary, the thermal design challenges included:

1. Widely varying thermal environment

2. Dense packaging and high power levels

3. Wide variation in component allowable temperatures

4. Minimal mass, power, telemetry, and control functionality

5. Selective redundancy

6. Thermal induced distortion

Each of these individually presented a significant challenge; integrating them into a tightly packaged optical instrument and developing a thermal vacuum test verification plan presented an even greater challenge to the thermal team.

\section{THERMAL CONTROL ARCHITECTURE}

Each distinct area of the GLAS thermal control architecture is discussed below:

\section{Loop Heat Pipes (LHPs)}

LHP technology was selected based on its high transport capability and the "variable" conductance necessary to maintain a constant evaporator temperature despite radiator temperature variations caused by the previously discussed environmental effects. One LHP is dedicated to the three lasers, of which only one is on at any time, and the second LHP controls the remaining dissipative components (gyroscope, star cameras, detectors, power supply/distribution and main electronics box).

Since survival conditions would result in a radiator temperature far below the freezing point of ammonia and insufficient heater power was available to prevent this, propylene $\left(\mathrm{C}_{3} \mathrm{H}_{6}\right)$ was selected as the working fluid.

To minimize thermal distortion of the optical benches, two complex traditional heat pipe networks were designed to collect the heat $(330 \mathrm{~W})$ from the densely packaged sources, transport it to one of the two LHP evaporators, and ultimately reject it to space from the OSR (Optical Solar Reflector) covered radiators.

The complexity of this network is seen in the "thermalcentric" LHP/heat pipe representation in Figure 5. Maintaining the various component temperatures within their respective allowable ranges (see Table 1) was a function of the component location in the network and the numerous thermal interfaces between it and the LHP evaporators.

\section{Receiver Telescope}

Thermal control of the beryllium receiver telescope figure 6) maintains temperatures with minimal thermal distortion; small gradients $\left(>0.5^{\circ} \mathrm{C}\right)$ in the primary mirror or larger gradients $\left(>5.0^{\circ} \mathrm{C}\right)$ in the tower supporting the secondary mirror could cause significant distortion or defocusing of the image.

\section{Etalon Filter}

Lastly, the temperature tuned Etalon Filter requires precise and adjustable temperature control to allow bandpass filtering of the faint return signal for the lidar channel detectors (SPCMs). The exact temperature needed varied between the engineering model and flight lasers. The Etalon Filter resides in a thermal oven and uses proportional heater control to provide very stable temperature control.

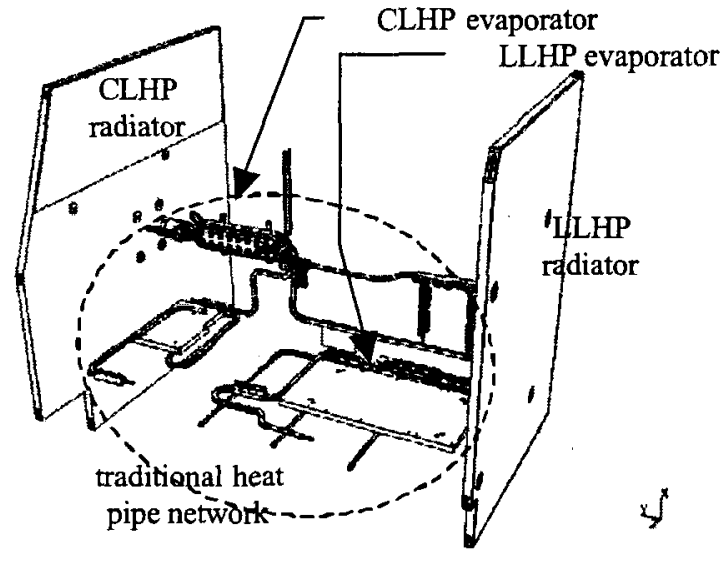

Figure 5 - GLAS Thermal Control Subsystem

Table 1 - Component Temperature Limits

\begin{tabular}{|c|c|c|c|c|c|}
\hline \multirow{2}{*}{$\begin{array}{l}\text { LHP Controlled } \\
\text { Component }\end{array}$} & \multirow{2}{*}{$\begin{array}{l}Q \\
t \\
y\end{array}$} & \multicolumn{4}{|c|}{ Temperature Range $\left({ }^{\circ} \mathrm{C}\right)$} \\
\hline & & $\begin{array}{l}\text { Min } \\
\text { Surv }\end{array}$ & $\begin{array}{l}\text { Min } \\
\text { Oper }\end{array}$ & $\begin{array}{l}\text { Max } \\
\text { Oper }\end{array}$ & $\begin{array}{l}\text { Max } \\
\text { Surv }\end{array}$ \\
\hline Lasers & 3 & 0 & 10 & 35 & 40 \\
\hline $\begin{array}{r}\text { Power Distribution } \\
\text { Unit }\end{array}$ & 1 & -20 & -10 & 35 & 60 \\
\hline $\begin{array}{r}\text { High Voltage } \\
\text { Power Supply }\end{array}$ & 1 & -20 & -10 & 35 & 60 \\
\hline $\begin{array}{r}\text { Main Electronics } \\
\text { Unit }\end{array}$ & 1 & -20 & -10 & 35 & 60 \\
\hline $\begin{array}{r}\text { Inertial Reference } \\
\text { Unit }\end{array}$ & 1 & -50 & 0 & 40 & 80 \\
\hline Star Tracker & 1 & -25 & 0 & 30 & 50 \\
\hline $\begin{array}{r}\text { Laser Reference } \\
\text { System }\end{array}$ & 1 & -25 & 0 & 30 & 50 \\
\hline $\begin{array}{r}\text { Laser Profiling } \\
\text { Array }\end{array}$ & 1 & -20 & -5 & 35 & 50 \\
\hline $\begin{array}{l}\text { Altimeter } \\
\text { Detectors }\end{array}$ & 2 & -10 & 0 & 30 & 60 \\
\hline $\begin{array}{l}\text { Single Photon } \\
\text { Counting Modules }\end{array}$ & 8 & -10 & 0 & 30 & 60 \\
\hline
\end{tabular}

\section{Heater Control}

Proportional Integral Differential (PID) heater control is used to maintain temperatures of the Receiver Telescope 
and Etalon Filter, while electronic thermostatic $\left(+/-0.1^{\circ} \mathrm{C}\right.$ bandwidth) control was used for the LHPs. All operational mode heater circuit controllers were designed to provide a large range of adjustability:

1. Although the LHP technology could provide a very stable temperature control, the specific set point within the $30^{\circ} \mathrm{C}$ range would be based on many factors, including the component dissipations, thermal network conductances, output energy temperature dependency of the flight lasers ${ }^{2}$, and optical bench thermal distortion effects on boresight alignment.

2. The Etalon heater controller had to accommodate the temperature tuning requirements of $E M$ and flight lasers over a $30^{\circ}$ range.

3. Due to a predicted shortage of heater power to maintain the telescope at ambient temperatures in the colder environments (higher beta angles), these heater circuits were designed to provide $-5^{\circ}$ to $25^{\circ} \mathrm{C}$ control.

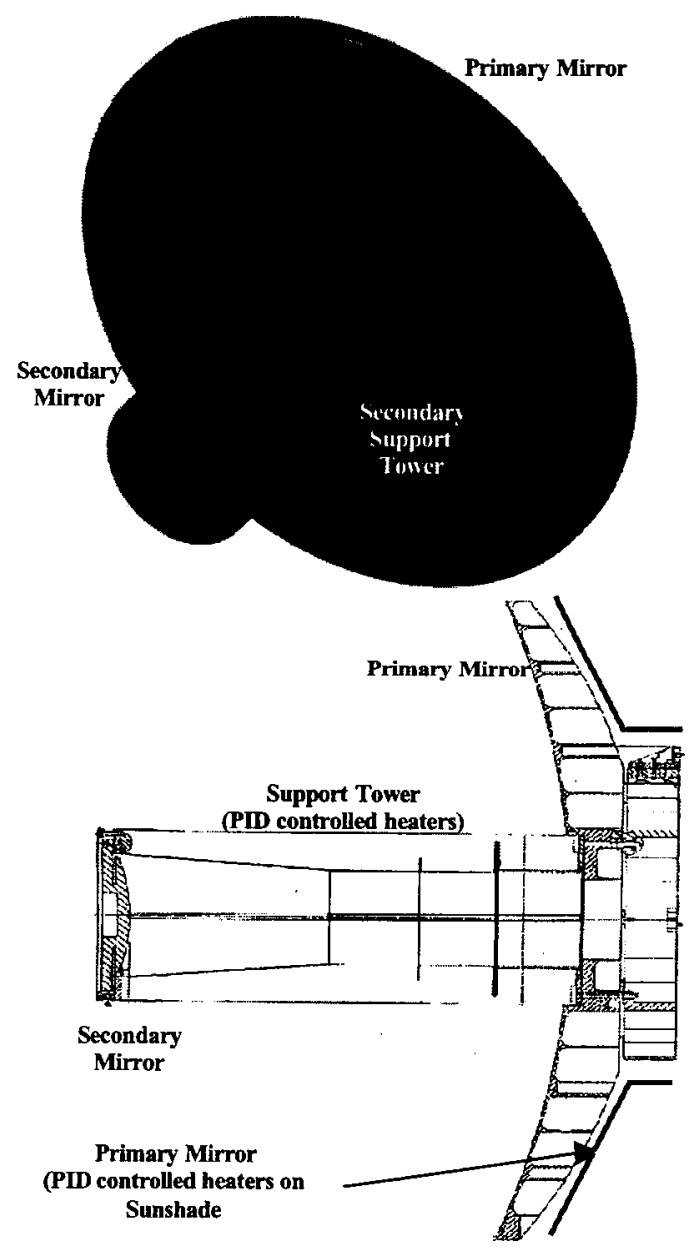

Figure 6 - Receiver Telescope Assembly

\footnotetext{
${ }^{2}$ GLAS peak laser output energy falls off significantly outside a narrow $\left(3^{\circ} \mathrm{C}\right)$ temperature range, known as the "sweet spot"
}

Survival heater circuits, powered continuously from the spacecraft, were used to maintain individual component temperatures during situations where GLAS was nonoperational. These heater strings were individually controlled with local thermostats at the controlled item.

Table 2 summarizes the operational and survival heater circuits used on GLAS.

Table 2 - GLAS Heater Circuit Summary

\begin{tabular}{|c|c|c|}
\hline Function & $\begin{array}{l}\text { Tset } \\
\left({ }^{\circ} \mathrm{C}\right)\end{array}$ & $\begin{array}{c}\text { Qhtr }(W) \\
\text { (max@28v } \\
\text { ) }\end{array}$ \\
\hline \multicolumn{3}{|l|}{ Operational Circuits: } \\
\hline Laser LHP & 0 to 30 & 22.0 \\
\hline Component LHP & -8 to 22 & 22.0 \\
\hline Etalon & 30 to 60 & 8.7 \\
\hline Telescope Tower & -5 to 25 & 16.4 \\
\hline Telescope Primary & -5 to 25 & 15.6 \\
\hline \multicolumn{3}{|l|}{ Survival Circuits: } \\
\hline Laser LHP & 4.5 & 19.2 \\
\hline Component LHP & -7.0 & 19.2 \\
\hline PDU/HVPS/MEU & -18 & 1.8 \\
\hline $\begin{array}{r}\text { Inertial Reference } \\
\text { Unit }\end{array}$ & -18 & 8.2 \\
\hline Star Tracker & -18 & 3.9 \\
\hline $\begin{array}{r}\text { Laser Reference } \\
\text { System }\end{array}$ & -18 & 6.5 \\
\hline $\begin{array}{r}\text { Laser Profiling } \\
\text { Array } \\
\end{array}$ & -18 & 5.3 \\
\hline $\operatorname{SPCM}(2)$ & -12.5 & 15.3 \\
\hline $\begin{array}{r}\text { Altimeter } \\
\text { Detectors (2) }\end{array}$ & -12.5 & 4.9 \\
\hline Lasers (3) & 0.5 & 2.6 \\
\hline Telescope & -57 & 19.4 \\
\hline
\end{tabular}

\section{THERMAL VERIFICATION PLAN}

Thermal development and verification of GLAS was based on the NASA General Environmental Verification Specification (GEVS). With serious schedule and cost consequences for failures at the instrument level of assembly, robust testing at the component level was required to mitigate this risk. While some components were difficult and iterative in design or qualification, this approach resulted in a robust, qualified system.

A thermal development was necessary only for the propylene LHPS and included engineering and prototype test beds. 
BREADBOARD - Early in the GLAS program, the capabilities of LHP technology was demonstrated by a small-scale breadboard test unit. Originally using ammonia $\left(\mathrm{NH}_{3}\right)$ as the working fluid, this unit was recharged and retested with propylene to characterize and compare performance to the more typical ammonia when the GLAS thermal design requirements changed.

DEVELOPMENT MODEL - This GLAS prototype unit (DMLHP) was designed to simulate the Laser LHP of the flight instrument (Figure 7) since it had the most stringent control requirements of the two planned flight systems. It was built and delivered in 1999 and tested extensively, with the following results:

- Routing the vapor and liquid return lines adjacent to each other, allowing the use of liquid-vapor coupling blocks to "pre-warm" the returning cold liquid, is a highly effective method in decreasing control power without compromising control in the hot case

- Stable $\left(+/-0.1^{\circ} \mathrm{C}\right)$ temperature control of a mass simulator was demonstrated

- A high flux starter heater was needed to overcome the effects of sensible heat, lost via the heat pipes that connect the large thermal mass to the evaporator, prior to start-up.

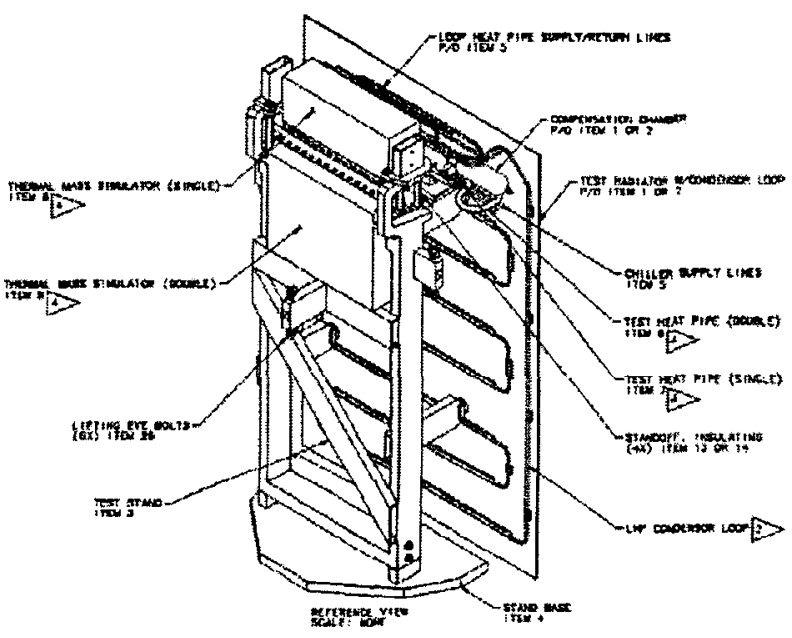

Figure 7 - Development Model LHP (DMLHP)

DMLHP test results (Reference 1) include:

- LHP system startup and operation with propylene

- LHP Temperature Control

- Optimization of control heater power using liquid-vapor line heat exchange blocks

- Adverse to reflux orientation operation

This testing successfully met all objectives.
FLIGHT UNITS - The flight units Figure 8) were initially delivered to GSFC in May 2000; acceptance testing included random vibration and thermal vacuum testing before delivery to I\&T. An Engineering Model structure was used as the vibration and thermal test fixture. Thermal vacuum acceptance testing uncovered a compensation chamber design problem due to an overly constrained packaging volume and inadequate fluid inventory (Reference 2) for 1-g testing. A redesign and subsequent retesting resulted in the desired high levels of performance. While these units performed well in ambient testing at the vendor, the problem was found only in thermal vacuum testing where the propylene undercharge, and resulting start-up difficulties, was apparent. Had these units not been tested until instrument thermal vacuum, the resulting schedule impact would have certainly threatened the mission.
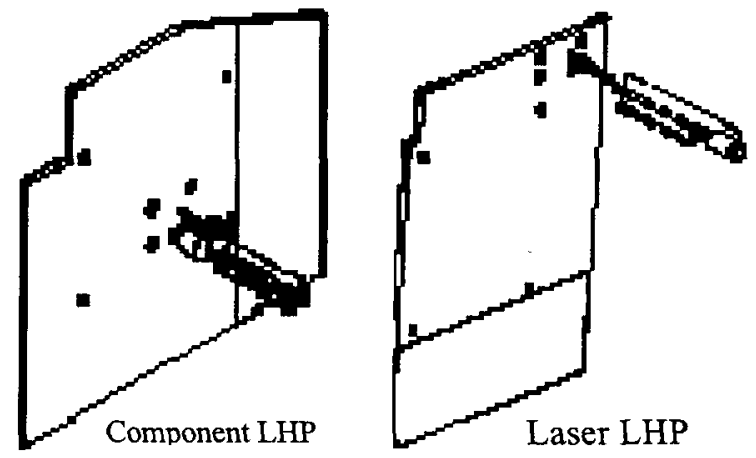

Figure 8 - Flight Loop Heat Pipes (LHPs)

The thermal design effort appropriately bounded the GLAS mission with hot and cold analysis cases using typical ranges for various analysis parameters. Component temperature requirements were based on these results, although the mission operations plan was to minimize thermal distortion by maintaining nearly constant optical bench and component temperatures throughout the mission. This would be achieved by using the same LHP setpoints for the life of the mission. Only minor changes were anticipated to counteract small temperature changes due to seasonal effects or spacecraft yaw maneuvers, different desired laser operating temperatures, and laser degradation.

It was anticipated that achievable operating ranges would decrease as the level of assembly increased due to the different limits (Table 1) of the many component controlled by the Component LHP and their location within the thermal network (Figure 9).

After a rigorous LHP development program, instrument thermal vacuum testing was completed in March 2002 as part of the environmental test verification program prior to integration onto the spacecraft bus. Subsequent testing of 
ICESat was completed in September 2002 in readiness for launch preparation.

INSTRUMENT THERMAL VACUUM TEST (ITV) provided the first opportunity to measure the GLAS optical performance in a space-like thermal environment. This testing included hot/cold balance data for model correlation and 4 qualification cycles. Since GLAS is powered OFF for up to 4 weeks during SC commissioning at the beginning of the mission, a survival plateau was included to verify adequate heater authority. Numerous boresight alignment measurements were taken at various temperature plateaus and during hot-cold transitions to understand temperature dependency of the optical alignment.

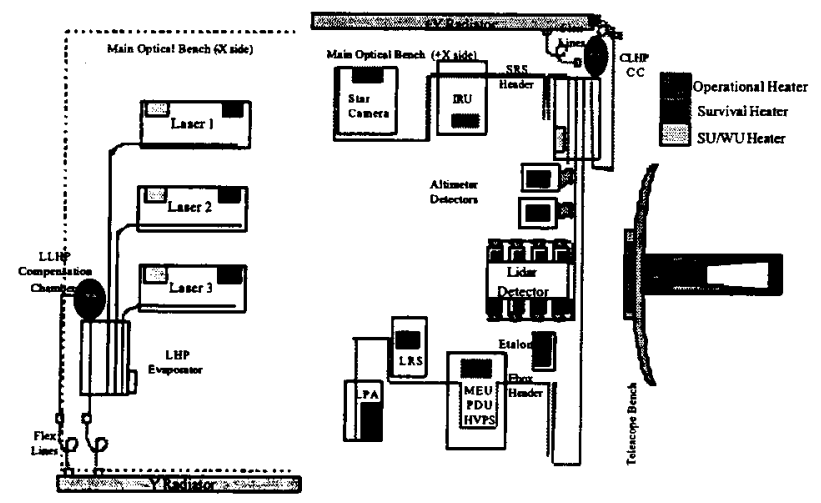

Figure 9 - Thermal Control Schematic

Thermal subsystem performance test results included:

1. LHP start-ups, setpoint adjustment, and stability in simulated sun / eclipse environments: Both LHPS started easily throughout the test; however, the CLHP start-ups were observed to increase in duration in the second phase of the tests, along with a $50 \%$ decrease in amperage. Post-test inspections confirmed that one of the two starter heaters had burned out due to a poor bond at the initial installation. Subsequent replacement of both CLHP starter heaters ensured a nominal bond. Separate life tests were conducted to demonstrate no degradation over 25 cycles, which represented approximately double the quantity required to complete $1 \& T$ and the mission. The LLHP uses a single starter heater and, since no damage was evident and the bondline strengthens with use, so it was not replaced. Setpoint adjustments were performed successfully in both directions.

2. Thermal stability of the Etalon filter at the planned $45.5^{\circ}$ setting was demonstrated in hot and cold plateaus.

3. Verification of survival heaters: Only a portion (9) of the 15 survival heaters activated during this phase of the test. This was expected since, as the system cooled, heat from the first circuits to activate would spread throughout the heat pipe network to the other components, thereby warming the entire system sufficiently until no further survival thermostats would activate. Since all heater circuits had been built up and individually tested in their final electrical configuration prior to installing on the flight hardware, actual installation posed little risk that they would not perform if needed on-orbit.

4. Determination of the thermal network conductances to reduce the hot-cold design range.

5. Demonstrate qualification margin: Qualification margin could not be demonstrated by simply changing the setpoint to $10^{\circ}$ above or below the "nominal" setpoint since component temperature ranges would likely be exceeded or the system optical performance would not be met due to excessive thermal distortions at these more extreme plateaus. Instead, qualification margin was defined as the margin in LHP setpoint adjustment (around the anticipated nominal setpoint) where optical boresight alignment requirements were met. Once the thermal network conductances were determined in the balance plateaus, the margin was determined by adjusting the LHP setpoints until the first component operational limit was reached. The average margin achieved was $7^{\circ} \mathrm{C}$ cold and $3^{\circ} \mathrm{C}$ hot.

6. Using this correlation of boresight ${ }^{3}$ data recorded over this qualification range and the setpoint adjustment capability of the LHP heater controllers, the ability to change the boresight alignment, which had become an issue, was demonstrated in thermal vacuum testing. This capability negated the need for a beam adjustment mechanism in the outgoing beam path that had been designed and built in parallel with the GLAS I\&T if it was needed.

Thermal vacuum testing provided an opportunity to rigorously assess the thermal control and instrument optical performance during thermal conditions that simulated the widely varying environments expected for the mission. The robustness of the thermal control subsystem was demonstrated, along with the unexpected ability to compensate for minor boresight misalignments by adjusting the optical bench temperatures indirectly using the Component LHP.

OBSERVATORY THERMAL VACUUM-TEST (OTV) After integration to the spacecraft, final thermal vacuum testing included hot/cold thermal balance plateaus and 2 cycles for demonstrating workmanship. Cost and launch schedule constraints minimized any deviation from or extension of the planned activities. Instrument goals for this test included:

\footnotetext{
${ }^{3}$ Boresight alignment refers to co-alignment of the outgoing laser beam to the receive path [includes distortions of the transmit path optics/mechanisms, and the receiver telescope and optics] in order for the return signal to be within the detector FOV.
} 
1. Verify final electrical interface connections

2. Compare boresight data to ITV results to determine effect of SC bus on boresight distortion.

3. Verify flight telemetry/command path and ability to adjust LHPs using Mission Operations Center control.

All of these goals were met.

ON-ORBIT PERFORMANCE - ICESat was successfully launched from Vandenberg AFB at $4: 45 \mathrm{pm}$ PST on January 12, 2003 into orbit with an initial $61^{\circ}$ beta angle. Following fairing ejection, the LHP radiators quickly cooled to approximately $-50^{\circ} \mathrm{C}$, but the optical and electronics components cooled much slower figure 10) until some of the sixteen survival heater circuits activated and maintained temperatures in the $-8^{\circ}$ to $6^{\circ} \mathrm{C}$ range; almost exactly as seen in test. GLAS remained in a survival state during spacecraft commissioning and checkout until February 2nd when the GLAS commissioning activities began with the CLHP and MEU tum-on.

On February 1st, 2003, NASA successfully started (Figure 12) the first tightly controlled propylene LHP in space. During the 15 minute contact period, the CLHP started within minutes of the starter heater being turned ON and ran in fixed conductance mode until the survival heater on the compensation chamber activated at $-7^{\circ} \mathrm{C}$ after which the system ran in a controlled, variable conductance mode.

Several orbits later, the MEU was powered on, the CLHP operational heater controller enabled, and the setpoint increased (via stored commands) to the anticipated nominal temperature Figure 15). On February 8th, the Laser LHP also started immediately when the starter heater was enabled Figure 14). Laser \#1 was activated and fired for the first time on February 20th, 2003.

The telescope heaters were soon activated to warm it from its cold survival soak of $-10^{\circ} \mathrm{C}$ to approximately $15^{\circ} \mathrm{C}$. Figure 16 shows the gradual warm up of the telescope. Interestingly, as seen in the plot, the temperature drops off somewhat at the end of eclipse due to voltage decrease from the discharging battery.

The turn-on of the Etalon Filter heaters and attainment of the $45.5^{\circ} \mathrm{C}$ setpoint is shown in also shown in Figure 16. Note the thermistor is saturated saturation prior to heater turn-on; the minimum readable temperature is $29.5^{\circ} \mathrm{C}$.

Since launch, GLAS has been within the almost continuous eclipse season, having about 33 minutes of shadow in every 98 minute orbit. The LHPs continue to provide selectable/stable temperatures for the lasers and other electronics. The stability of the lasers and other components during these transients is shown in Figure 11.

\section{CONCLUSION}

The GLAS instrument is NASA's first application of propylene LHP technology that, as the core of the thermal control architecture, provides selectable/stable temperature levels for the lasers and other electronics.

Incremental verification of the TCS, throughout component development and $1 \& \mathrm{~T}$, resulted in a robust design and provided efficient screening for problems that could have had major schedule or science impacts if discovered at higher levels of assembly. The unqualified success achieved for the GLAS mission should reinforce this methodology as the standard to strive for in technology development.

Flight data confirms the ground testing performance with only minor differences manifested in zero gravity. After 5 months of operations, the GLAS thermal control subsystem continues to perform as expected. Continuous performance throughout the 5-year mission will yield a better understanding of LHP operation and provide a wealth of data that can be used as a heritage basis for future missions.

\section{ACKNOWLEDGEMENTS}

The authors gratefully acknowledge the efforts of the Thermal Engineering and Environmental Test groups at Goddard Space Flight Center, especially David Steinfeld, Walter Ancarrow, Sally McCann, Janci Viegas, and Chris Johnson for their support during the test and mission operations campaigns.

\section{REFERENCES}

1. "Geoscience Laser Altimeter System (GLAS) DMLHP TV Testing Final Report", NASATTP-2000-209898 [C. Baker]

2. "System Accommodation of the Propylene Loop Heat Pipes For the Geoscience Laser Altimeter System (GLAS) Instrument", ICES 2001 [E. Grob]

\section{CONTACTIAUTHOR INFO}

For more information, please contact:

Eric W. Grob

BSME 1980 West Virginia University

MSME 1989 Drexel University

NASA Goddard Space Flight Center, Code 545

Greenbelt, MD 20771

Tel: (301) 286-6488

Fax: (301) 286-1704

Eric.W.Grob@nasa.gov 


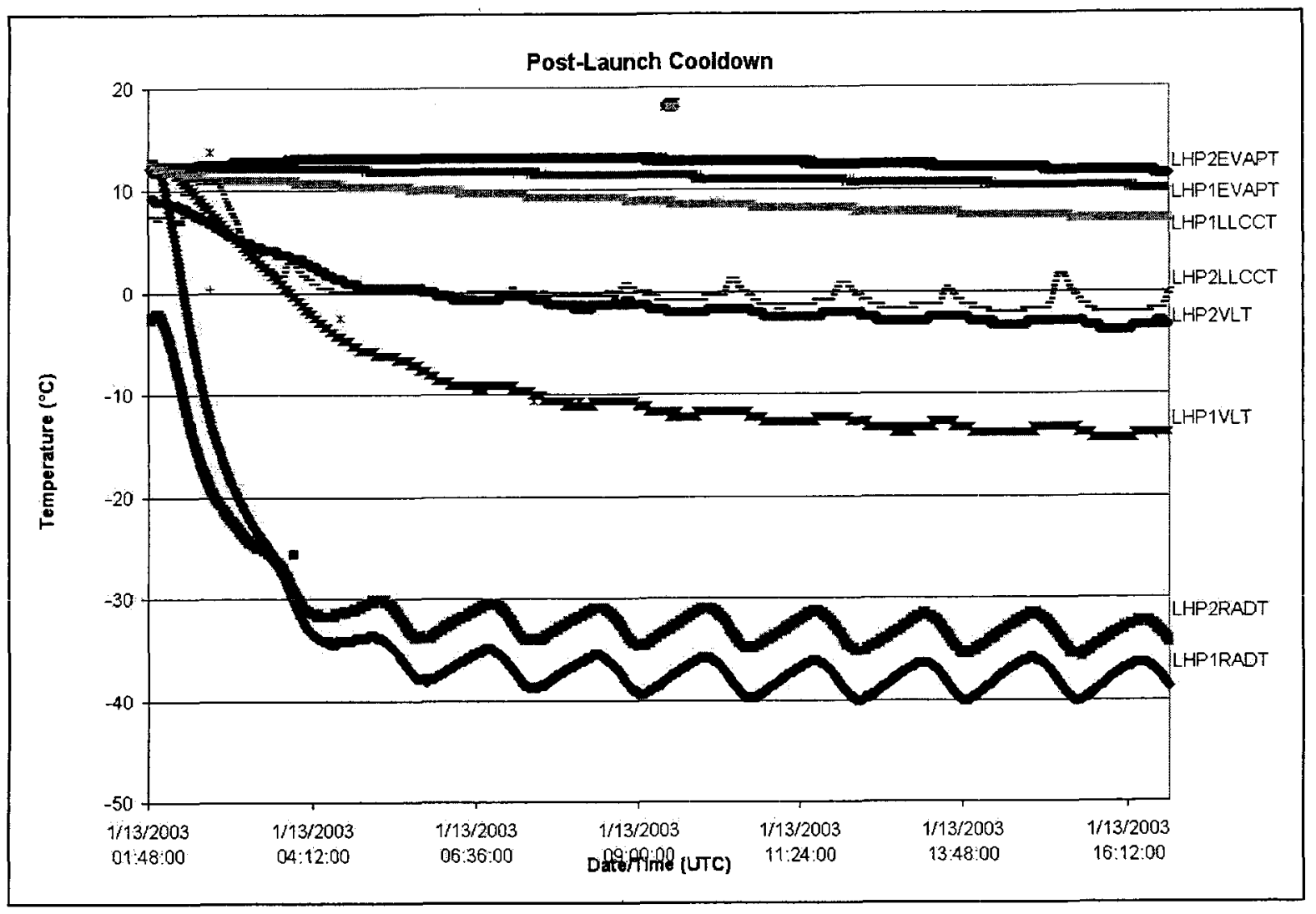

Figure 10 - Post-Launch Cooldown to Survival Heater Activation

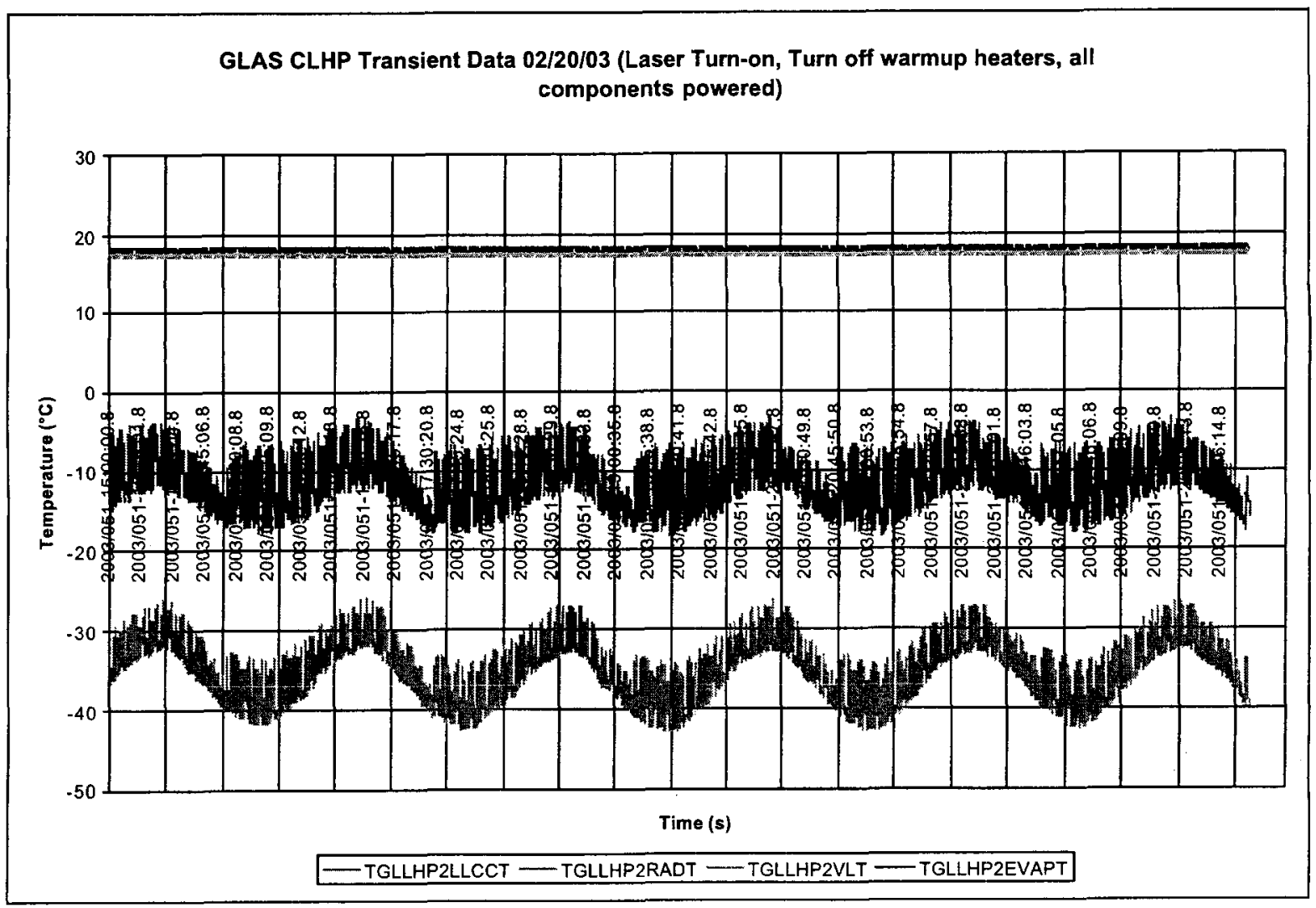

Figure 11 - Stable Operation of CLHP During Eclipse Transients 


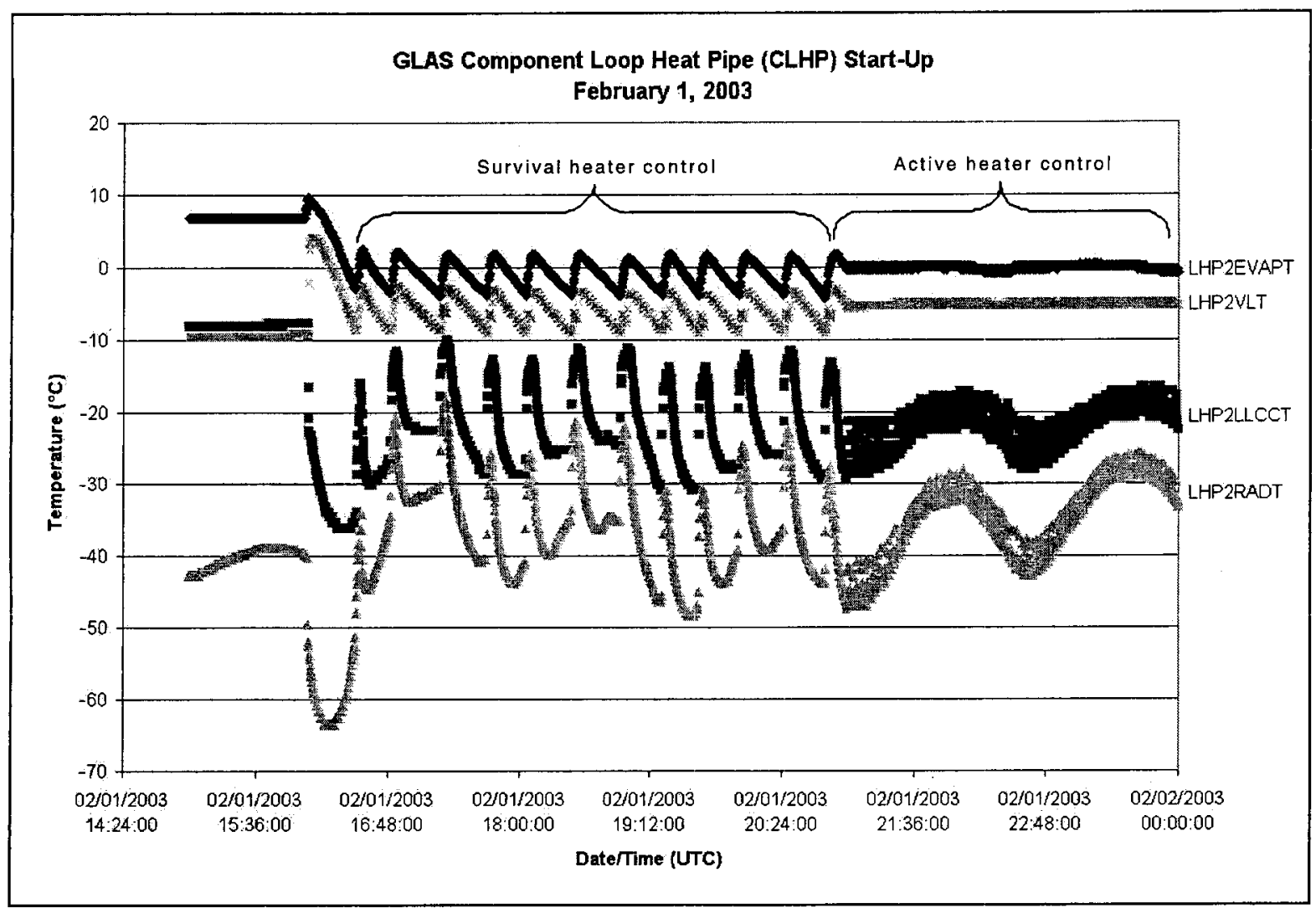

Figure 12 - Component Loop Heat Pipe Start-Up

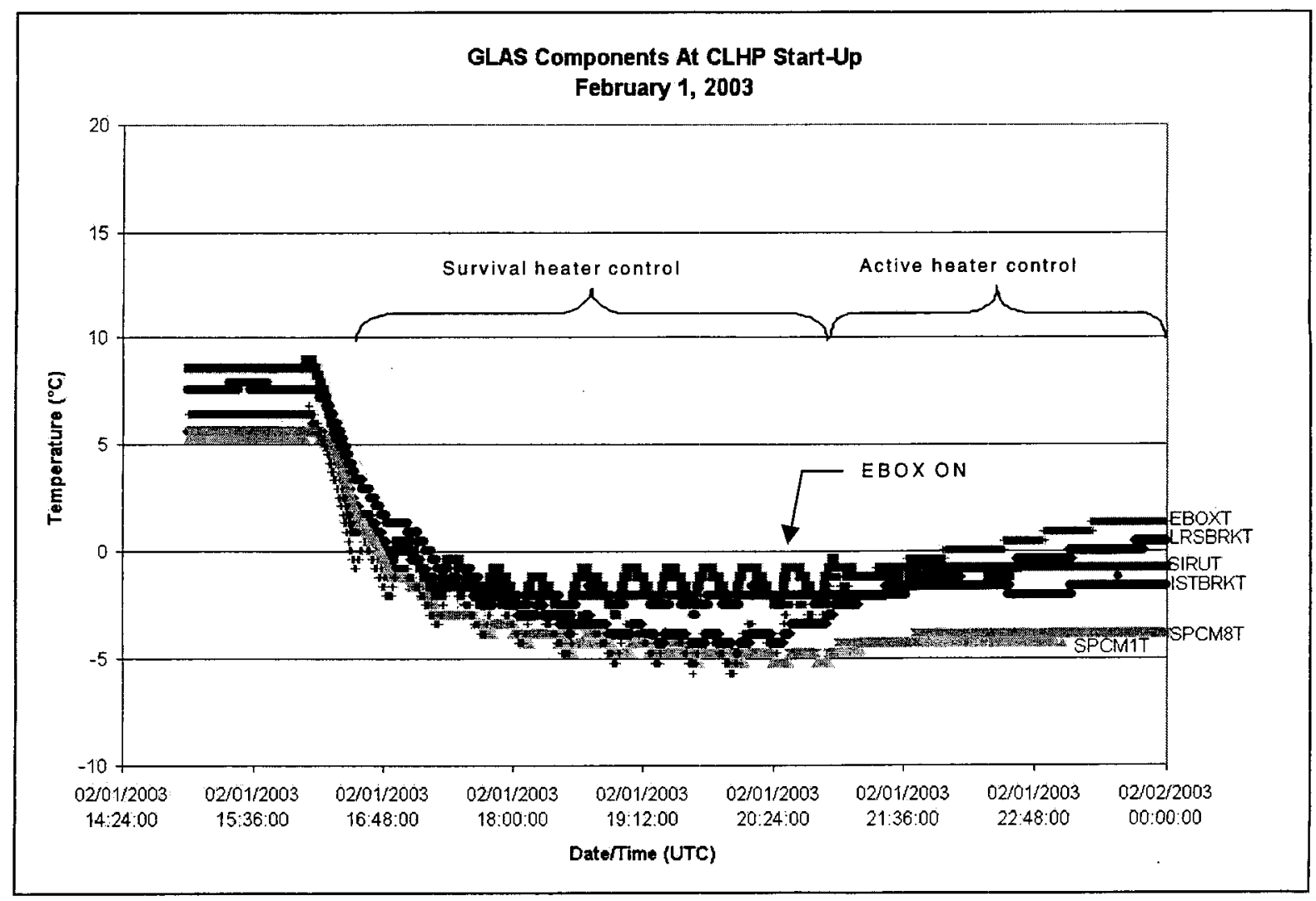

Figure 13 - Component Response to CLHP Start-Up 


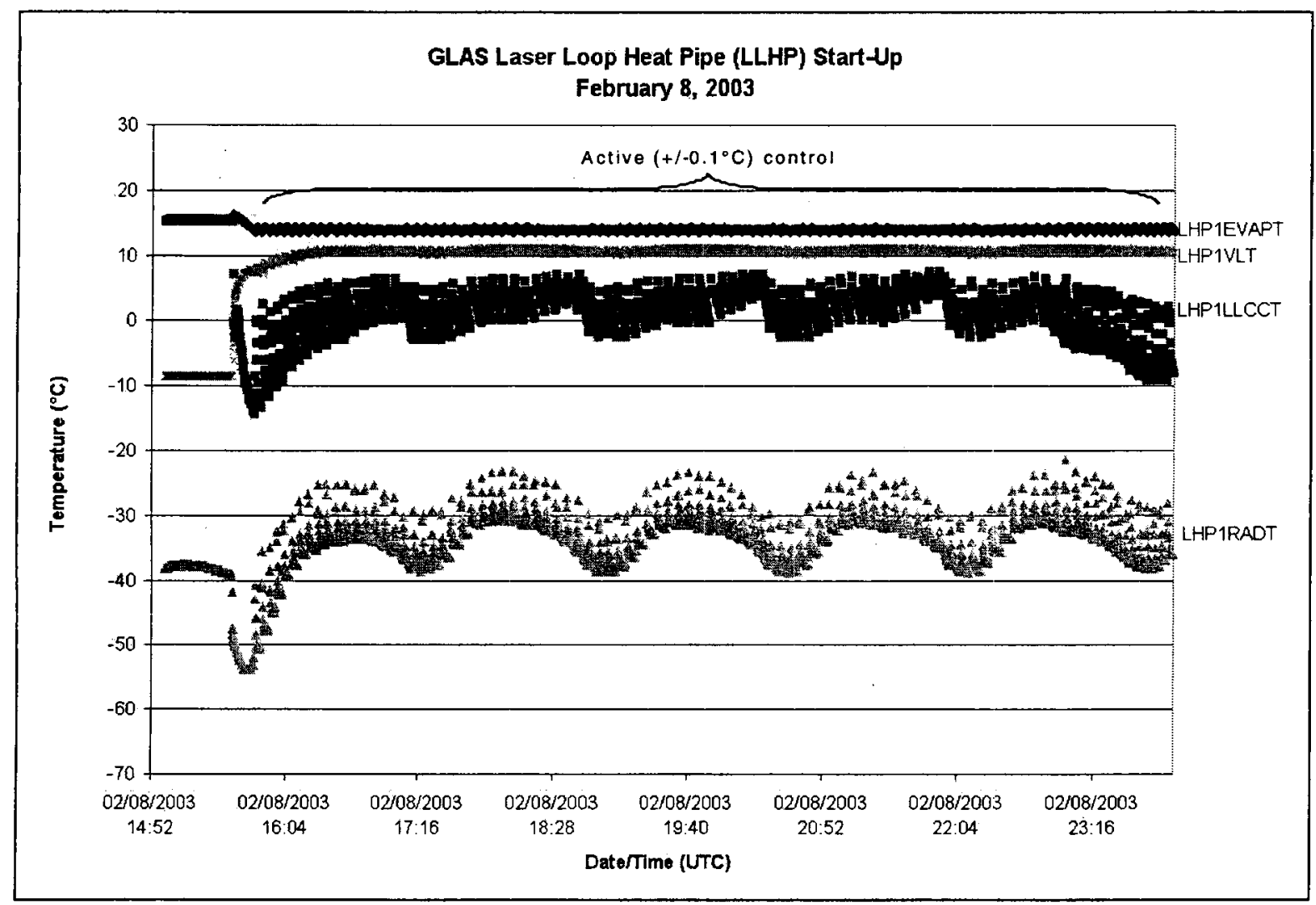

Figure 14 - Laser Loop Heat Pipe Start-Up

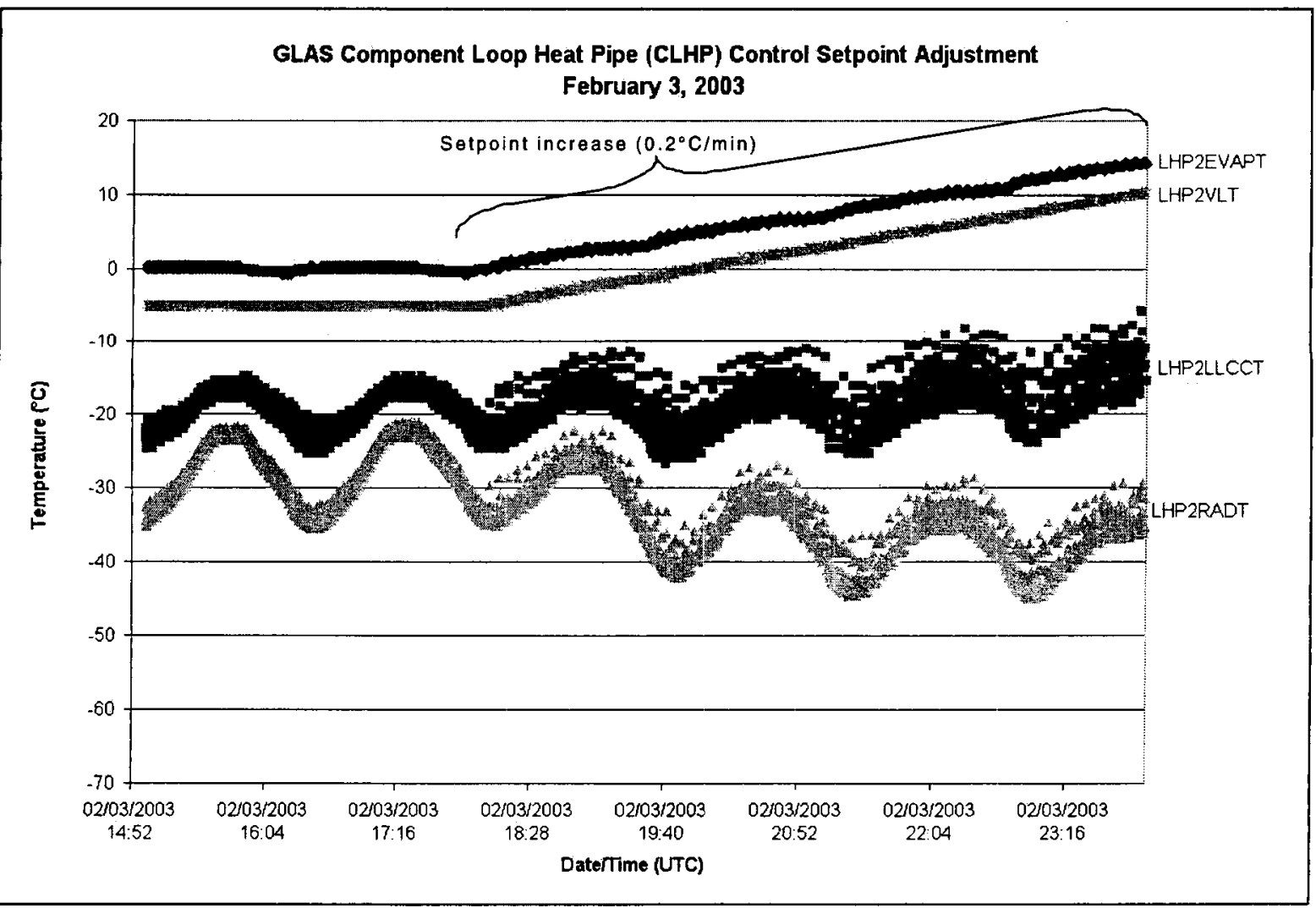

Figure 15 - Component Loop Heat Pipe Control Setpoint Adjustment 


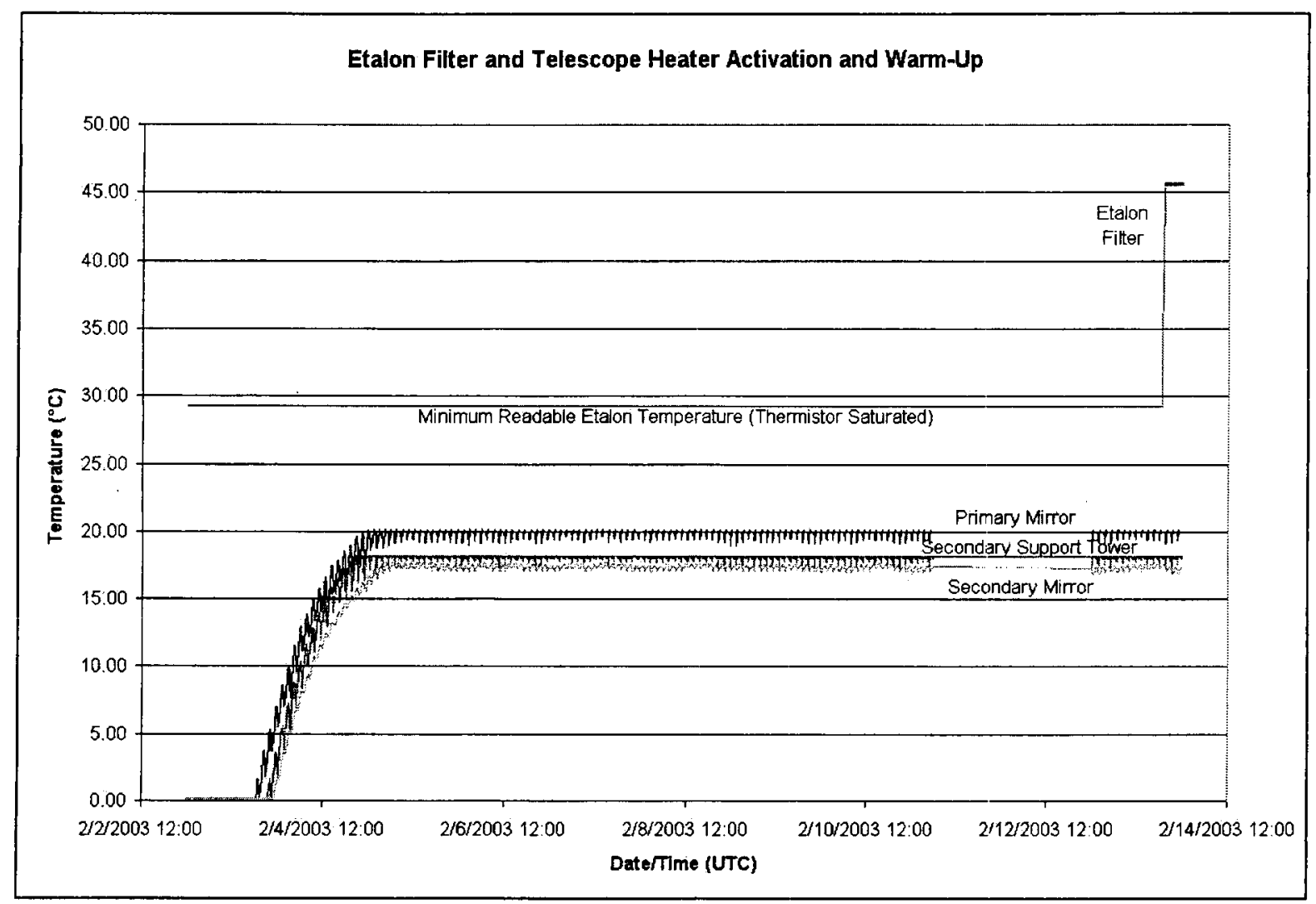

Figure 16 - Etalon Filter and Telescope Operational Heater Activation 